\title{
Chapter 8 \\ Radiation Measurement in East Japan in 2011 After the Fukushima Nuclear Accident
}

\author{
Takumi Kubota, Jun-ichi Hori, Nobuhiro Sato, Koichi Takamiya, \\ Tomoko Ohta, and Yasunori Mahara
}

\begin{abstract}
Air dose rates were measured inside a car with an ion chamber detector across Fukushima Prefecture from March 19 to 22, 2011. The dose rate along the Tohoku Expressway ranged from 2 to $6 \mu \mathrm{Sv} / \mathrm{h}$. Relatively high values were obtained around Nihonmatsu City. The dose rate dipped to an exceptionally low value inside a tunnel to what was probably the normal background value before the Fukushima nuclear accident. The dose rate in Fukushima City ranged from 2 to $9 \mu \mathrm{Sv} / \mathrm{h}$. High values were obtained in the center of the city. The dose rates along the Banetsu Expressway and in Samegawa Village located in the Abukuma highlands were very low at $1.5-3$ and $1 \mu \mathrm{Sv} / \mathrm{h}$, respectively. During our stay in Fukushima, external and internal exposure was evaluated at 0.1 and $0.0327 \mathrm{mSv}$, respectively.

A commercially available GM-tube detector calibrated with a ${ }^{137} \mathrm{Cs}$ standard source was used to determine the status of environmental radioactive contamination caused by the Fukushima nuclear accident. The calibration was achieved with a quadratic correction function for dose rates up to $4 \mu \mathrm{Sv} / \mathrm{h}$. The calibrated GM-tube detector was used for measuring air dose rates and ground surface contamination in East Japan. Measurements were taken inside a car and a bullet train as well as outdoors from March to August 2011. The dose rates measured inside a vehicle along the Tohoku Expressway (in May) and in the Tohoku Shinkansen (in August) were as much as 1.0 and $0.25 \mu \mathrm{Sv} / \mathrm{h}$, respectively. The measurement results agreed well with the official data obtained using a $\mathrm{NaI}$ scintillation counter, demonstrating that a calibrated GM-tube detector can be an effective tool for measuring radioactivity.
\end{abstract}

\footnotetext{
T. Kubota $(\varangle) \bullet$ J.-i. Hori $\bullet$ N. Sato $\bullet K$. Takamiya

Research Reactor Institute, Kyoto University, Kumatori, Osaka 590-0494, Japan

e-mail: t_kubota@rri.kyoto-u.ac.jp

T. Ohta

Hokkaido University, Sapporo, Hokkaido 060-8628, Japan

Y. Mahara

Kyoto University, Kyoto 615-8246, Japan
} 
Keywords Air dose rate $\bullet$ GM-tube detector $\bullet$ Ion chamber detector $\bullet$ Mobile radiation survey $\bullet$ Surface contamination

\subsection{Introduction}

As a result of the Great East Japan Earthquake, a large amount of radioactive material was accidentally released from the Fukushima Daiichi Nuclear Power Plant (NPP). The Fukushima nuclear accident required radiation screening and medical support for refugees and residents from a very early stage. As one of these activities, we traveled to Fukushima Prefecture to perform radiation screening. The air dose rate inside a car was measured during the trip. The external and internal exposure during our stay in Fukushima for the screening activity was also measured. The measurement results are described in this report.

Many reports concerning radioactivity [1-3], including surface contamination, radioactive concentration, and air dose rate, were published by researchers, mass media outlets, and the government. Additional information was obtained and published by some members of the general population who used commercially available detectors, mainly Geiger Mueller tube (GM-tube) detectors, without calibration. However, these detectors often exhibited a considerable amount of interindividual variability, and the measurement results sometimes caused unnecessary confusion. In this study, a calibrated GM-tube detector was used for measuring radioactivity in East Japan, and the measurement results were compared with official data provided by the Japanese government.

\subsection{Materials and Methods}

Two commercially available detectors, a GM-tube detector and an ion chamber detector, were in-house calibrated. The GM-tube detector ("Radiation Alert Inspector+," SE International, which is co-owned by International Medcom) was calibrated using a standard ${ }^{137} \mathrm{Cs}$ radioactive source (\#JDSR9518; $1.47 \times 10^{-12} \mathrm{C} \mathrm{kg} / \mathrm{s}$ at $1 \mathrm{~m}, 0.225 \mu \mathrm{Sv} / \mathrm{h}$ at $1 \mathrm{~m}$ ), which provided dose rates of 3.6, 0.9 , and $0.4 \mu \mathrm{Sv} / \mathrm{h}$ at distances of $0.25,0.50$, and $0.75 \mathrm{~m}$ from the source, respectively. The ion chamber detector (Aloka ICS-313) was calibrated with a standard ${ }^{226} \mathrm{Ra}$ radioactive source $(85 \mu \mathrm{Sv} / \mathrm{h}$ at $1 \mathrm{~m})$. During the calibration, the detector and the radioactive source were placed on a 1-m-high plastic table.

The calibrated ion chamber was used to measure dose rate $(\mu \mathrm{Sv} / \mathrm{h})$ inside a car throughout our following radiation screening activity. On March 19, 2011, we left Kumatori Town, Osaka, in the morning and arrived at Iizaka Onsen in Fukushima City that night; on March 20, we departed from Fukushima City and arrived at Nakoso High School in Iwaki City (southeast part of Fukushima Prefecture) for radiation screening, and then returned to Fukushima City that night; on March 21 and 22, 
we departed from Fukushima City and traveled to Shirakawa City (southern part of Fukushima Prefecture) and Samegawa Village (only March 21), and then returned to Fukushima City that night; finally, on March 23 we returned to Kumatori Town by bus, airplane, and train. Except for the last day, we traveled by the same delivery cargo van on all other days.

The calibrated GM-tube detector measured the dose rate just above the ground surface and at a height of $1 \mathrm{~m}$ from the ground surfaces. The locations and dates of the radioactive measurements were as follows: Ueno Park in Tokyo on March 30, 2011; the Tohoku Expressway from Tochigi to Miyagi on May 26, 2011; the Tohoku Shinkansen bullet train from Saitama to Koriyama, Fukushima in August 2011; and Namie and its surrounding area in Fukushima in August 2011.

The resulting personal external and internal exposure in radiation screening activity was evaluated by a glass dosimeter (Chiyoda Technol) and by MONDAL with results from a $\mathrm{NaI}$ scintillation whole-body counter (detector size: $8^{\prime \prime} \Theta \times 4^{\prime \prime} \mathrm{t}$ ), respectively. In whole-body counting, the measuring time was $10 \mathrm{~min}$ and the detection limits of ${ }^{131} \mathrm{I}$ and ${ }^{137} \mathrm{Cs}$ were 20 and $500 \mathrm{~Bq}$, respectively. During this activity, we wore new masks every morning to avoid internal exposure, and the radioactivity of masks was measured for 3,600 s with two GE semiconductor detectors (Princeton Gamma-Tech IGC3019 and Seiko EG\&G 7600-0001). The radioactivity of masks was defined as the average value calculated from the two calibration equation for a thin membrane filter of 50-mm diameter and a charcoal filter of $60-\mathrm{mm}$ diameter and 20-mm thickness to take into account the effect of solid angle and then corrected for decay to the day when masks were used. The detection limits of ${ }^{132} \mathrm{Te},{ }^{131} \mathrm{I}$, ${ }^{134} \mathrm{Cs},{ }^{136} \mathrm{Cs}$, and ${ }^{137} \mathrm{Cs}$ were $0.3,0.3,0.4,0.7$, and $0.4 \mathrm{~Bq}$, respectively.

\subsection{Results and Discussion}

\subsubsection{Calibration}

The GM-tube detector measured the radiation fields regulated by the ${ }^{137} \mathrm{Cs}$ standard radioactive source. Measurements were taken ten times every minute. The background air dose rate measured using a NaI scintillation counter was $0.09 \mu \mathrm{Sv} / \mathrm{h}$; this value was added to the air dose regulated from the standard source. The temporal change in the measurement is presented in Table 8.1. The measurement values barely approached a certain value correlated with the actual air dose rate, in contrast to the values obtained using the scintillation counter, and their variation coefficient decreased with the air dose rate. The GM-tube detector used here showed an instrument reading with a maximum error of $\pm 20 \%$.

The GM-tube detector was calibrated with certified values from 0.09 to $3.69 \mu \mathrm{Sv} / \mathrm{h}$ to obtain the following calibration equation:

$$
Y=-0.0409 X^{2}+0.9238 X-0.0264
$$


Table 8.1 Temporal change in instrument reading

\begin{tabular}{|c|c|c|c|c|c|c|c|c|c|c|}
\hline \multirow{2}{*}{$\begin{array}{l}\text { Certified value } \\
(\mu \mathrm{S} v / \mathrm{h})\end{array}$} & \multicolumn{10}{|c|}{ Instrument reading } \\
\hline & $\# 1$ & $\# 2$ & $\# 3$ & $\# 4$ & $\# 5$ & $\# 6$ & $\# 7$ & $\# 8$ & $\# 9$ & $\# 10$ \\
\hline 0.09 & 0.149 & 0.161 & 0.125 & 0.089 & 0.143 & 0.113 & 0.119 & 0.119 & 0.107 & 0.089 \\
\hline 0.49 & 0.527 & 0.539 & 0.569 & 0.581 & 0.461 & 0.611 & 0.640 & 0.575 & 0.706 & 0.539 \\
\hline 0.99 & 1.132 & 1.220 & 1.114 & 1.246 & 1.084 & 1.192 & 1.090 & 1.060 & 1.282 & 1.330 \\
\hline 3.69 & 5.431 & 5.250 & 5.238 & 5.413 & 5.335 & 5.262 & 5.262 & 4.708 & 5.244 & 5.112 \\
\hline
\end{tabular}

Fig. 8.1 Calibration of a GM-tube detector

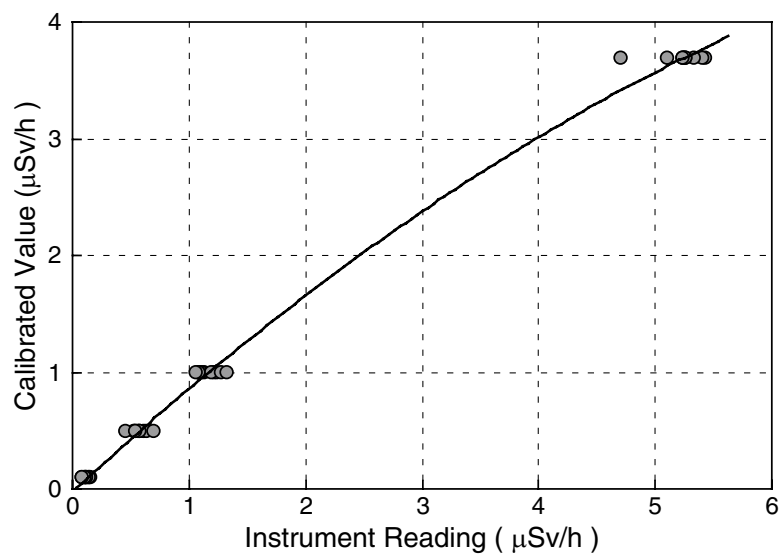

where $Y$ and $X$ represent the calibrated value and the instrument reading, respectively. Figure 8.1 clearly shows the calibration equation as a quadratic rather than a linear function. The fact that the function is convex upward suggests that the GM-tube detector would underestimate the radiation fields at higher air dose rate conditions.

\subsubsection{Air Dose Rate}

\subsubsection{Along Tohoku Expressway}

During the screening activity, we traveled on the Tohoku Expressway in Fukushima Prefecture five times. The change of air dose rates is shown in Fig. 8.2. The dose rates obtained on March 19 were low, and they increased with time. The degree of increment, however, fluctuated greatly. It seemed that radioactive materials released still wafted over and were not yet strongly adsorbed into the ground. At the Adatara service area in Motomiya City around 7:00 p.m. on March 19, we observed the following dose rate change: the initial value was $2 \mu \mathrm{Sv} / \mathrm{h}$, it peaked at $4 \mu \mathrm{Sv} / \mathrm{h}$, and finally decreased to $2.7 \mu \mathrm{Sv} / \mathrm{h}$. This short-period change might have shown that a small radioactive plume had passed over. A radioactive peak seemed to have formed 


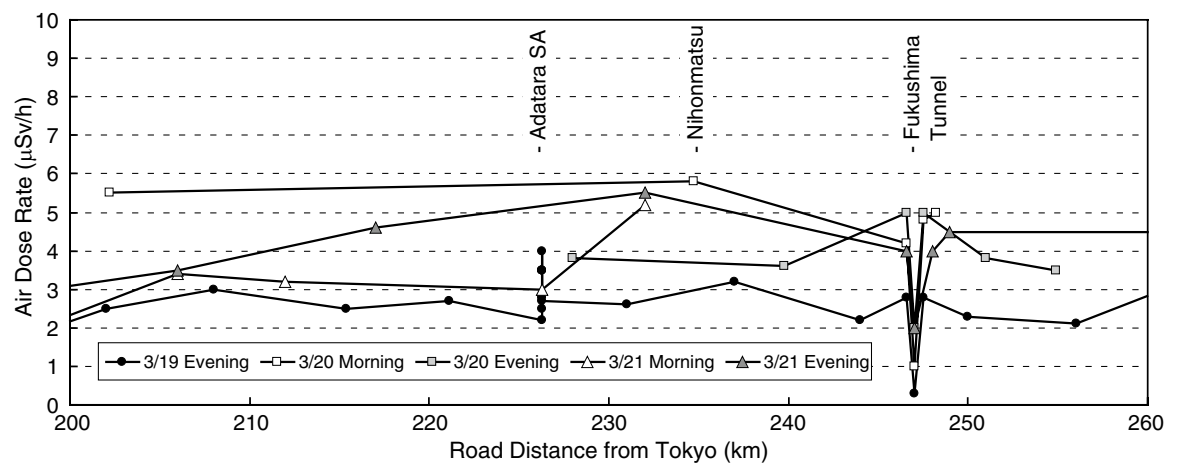

Fig. 8.2 Change in air dose rate along Tohoku Expressway

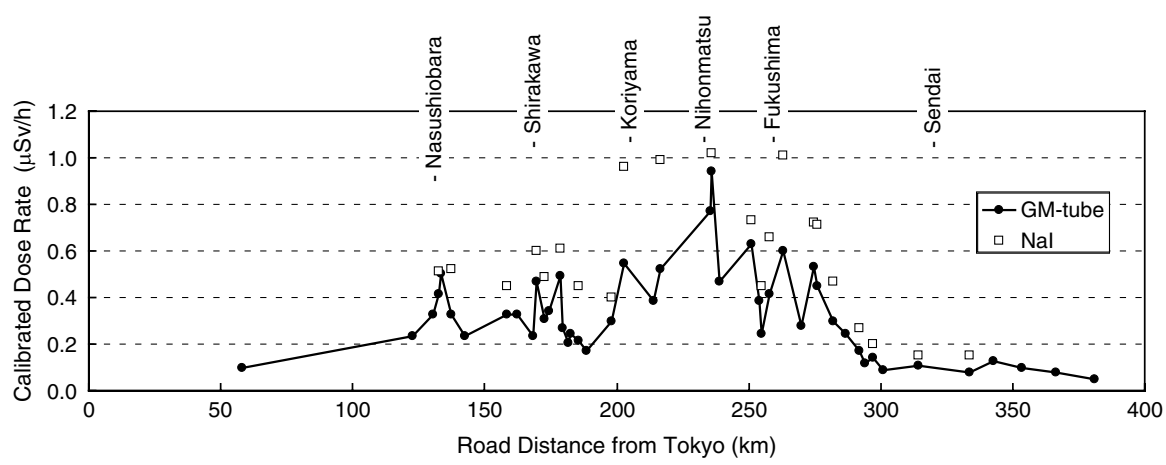

Fig. 8.3 Dose rate inside a car along the Tohoku Expressway. Closed circles and open squares indicate data from the Geiger Mueller tube (GM-tube) measurements and official material, respectively

around Nihonmatsu where a high air dose rate on the expressway was reported in May 2011 by the Fukushima Prefecture government [4]. The dose rate dipped inside the Fukushima tunnel, about $900 \mathrm{~m}$ in length, through Mt. Atago in Fukushima City. Although dose rates inside the long tunnel rapidly decreased because of the negligible direct radioactive deposition, these values gradually increased with time as the result of transit of contaminated traffic and air.

The calibrated dose rates obtained inside a car along the Tohoku Expressway on May 26, 2011, are shown in Fig. 8.3. A peak dose rate of $0.94 \mu \mathrm{Sv} / \mathrm{h}$ was recorded at Nihonmatsu City, which is $55 \mathrm{~km}$ from the Fukushima Daiichi NPP and is the nearest point to the plant on the Tohoku Expressway. A similar measurement was carried out using a NaI scintillation counter on May 22, 2011; this was part of the official data published by the Fukushima Prefecture government [4]. The results of the long-distance mobile radiation survey (shown in Fig. 8.3) indicate that both measurements provide comparable results, except for three points in Fukushima and Koriyama City, and that they validate the use of calibrated GM-tube counting. 
Fig. 8.4 Measure of contamination based on distance from Fukushima Daiichi Nuclear Power Plant (NPP)

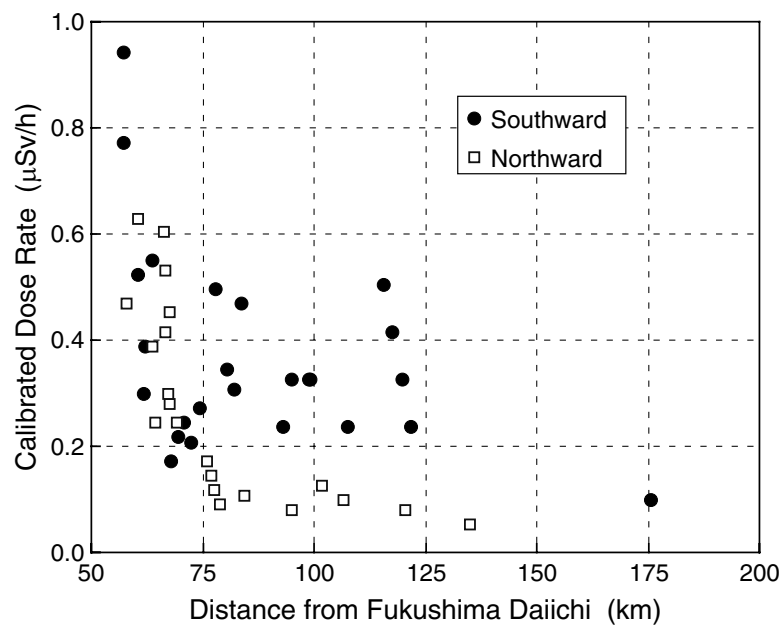

Table 8.2 Comparison of dose rate between in Tohoku Shinkansen and on the Tohoku Expressway

\begin{tabular}{lll}
\hline Location & Calibrated dose rate $(\mu \mathrm{Sv} / \mathrm{h})$ & \\
\hline Nasushiobara & 0.50 & 0.20 \\
Shirakawa & 0.47 & 0.15 \\
Koriyama & 0.55 & 0.25 \\
Date & May 2011 & August 2011 \\
Route & Tohoku Expressway & Tohoku Shinkansen \\
\hline
\end{tabular}

A comparison of dose rate trends north and south of Nihonmatsu City (Fig. 8.4) provided the status of the radioactive contamination spread in the environment. Both trends show a similar decrease up to $75 \mathrm{~km}$. Different trends, however, are shown from 75 to $125 \mathrm{~km}$. The values obtained in the northern location decreased to a certain constant value, defined here as the background value. In contrast, the values obtained in the southern location are two to five times higher than the background value and exhibit some small peaks, which could be considered hot spots. These trends indicate that larger amounts of radioactive material were widespread in the southern location.

\subsubsection{Tohoku Shinkansen}

The results of measurements carried out in August 2011 aboard the Tohoku Shinkansen (bullet train), which runs almost parallel to the Tohoku Expressway, are listed in Table 8.2. The dose rates obtained in the Shinkansen decreased to $40 \%$ of those obtained along the expressway in May 2011. According to "Extension Site of the Distribution Map for Radiation Dose" [5], the radiation dose at three locations decreased from a range between 0.5 and $1.0 \mu \mathrm{Sv} / \mathrm{h}$ to a range between 0.2 and 
Fig. 8.5 Temporal variation of radiation dose rate in Fukushima City

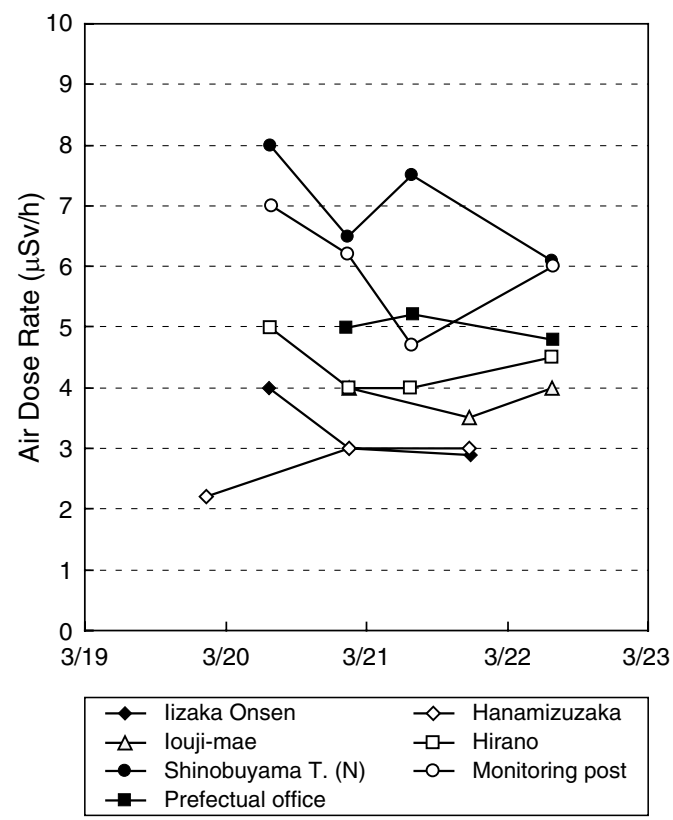

$0.5 \mu \mathrm{Sv} / \mathrm{h}$ in the same period. The same decreasing tendency suggests the validity of using a calibrated GM-tube for radiation dose measurement in a rapidly moving vehicle at a speed of around $200 \mathrm{~km} / \mathrm{h}$.

\subsubsection{Fukushima City}

In Fukushima City as well as on the Tohoku Expressway, air dose rates measured several times on the same street between the Prefectural office (center of Fukushima City) and Iizaka Onsen (northern part of the city) are shown in Fig. 8.5. The dose rate in the center of the city was higher, and the highest values were obtained at the north end of the Shinobuyama tunnel, about $700 \mathrm{~m}$ in length through Mt. Shinobuyama (altitude $275 \mathrm{~m}$ ). The distance between the prefectural office and Iizaka Onsen is about $9 \mathrm{~km}$, and they are located 60 and $64 \mathrm{~km}$ from the Fukushima Daiichi NPP, respectively. In spite of similar distances from Fukushima Daiichi, a large variation in the air dose rate at these locations was observed. Further, a dip in the air dose rates inside the Shinobuyama tunnel was observed: the rates were 6-8 $\mu \mathrm{Sv} / \mathrm{h}$ at both ends and decreased to $1.5-2 \mu \mathrm{Sv} / \mathrm{h}$ at the center of the tunnel.

\subsubsection{Across Fukushima Prefecture}

We made a round trip to Iwaki City on March 20. The temporal change in the air dose rate is shown in Fig. 8.6. The rates along the Banetsu Expressway and in Iwaki 
Fig. 8.6 Change in air dose rate on 1 day of screening activity

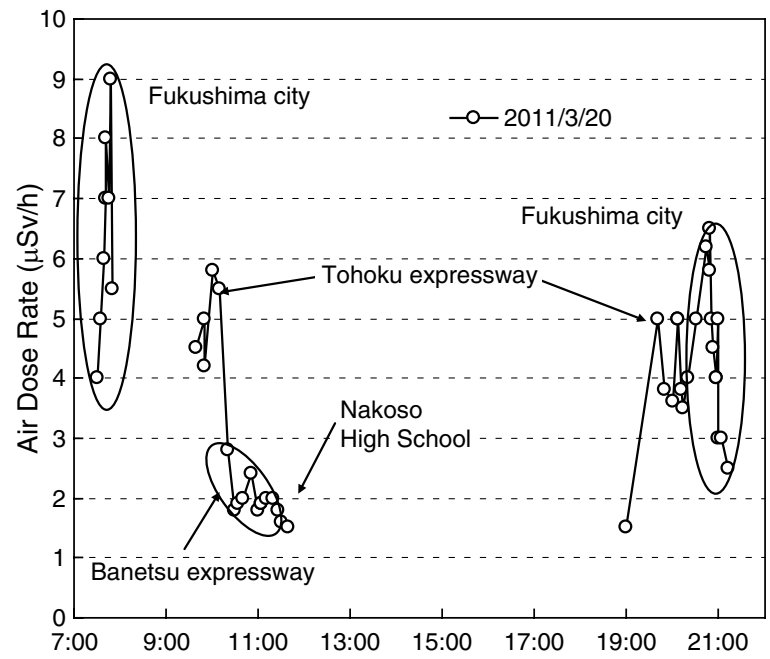

City were considerably lower than those along Tohoku Expressway and in Fukushima City as already described. This trend across Fukushima Prefecture agreed with the results from airborne monitoring in April 2011 [6], which would suggest the distribution of contamination (mainly radioactive cesium) had roughly stabilized since March 20 at the latest.

Screening activity was conducted in Samegawa Village and Shirakawa City on March 21 and 22, and their dose rates were approximately 1 and $2 \mu \mathrm{Sv} / \mathrm{h}$, respectively. Low air dose rates were obtained on both the Banetsu Expressway and in Samegawa Village in the Abukuma highlands. The Abukuma highlands served as a barrier to the diffusion of the radioactive plume released from the Fukushima Daiichi NPP [7]. Consequently, the plume streamed along the basin at the foot of the highland where Fukushima City and Tohoku Expressway are located and high radioactive contamination was detected.

\subsubsection{Surface Contamination}

The instrument readings (uncalibrated value) obtained near the ground surface in and around Ueno Park, 2 weeks after the nuclear accident, are shown in Fig. 8.7. Some of the values obtained are beyond the calibration value, and hence, the original instrument reading is adopted. The measurement values and the width of their distribution increased in the following order: park ground, road asphalt, and street gully. The removal of several millimeters of the surface of park ground provided a decrease in the measured dose rate by a factor of $2-4$, which showed that radioactive material contaminated only the park ground surface and barely penetrated deeper. The nature of the ground surface affected the measurement values, although all the 
Fig. 8.7 Amount of relative radioactivity (instrument reading indicated in $\mu \mathrm{Sv} / \mathrm{h}$ ) obtained near the ground surface

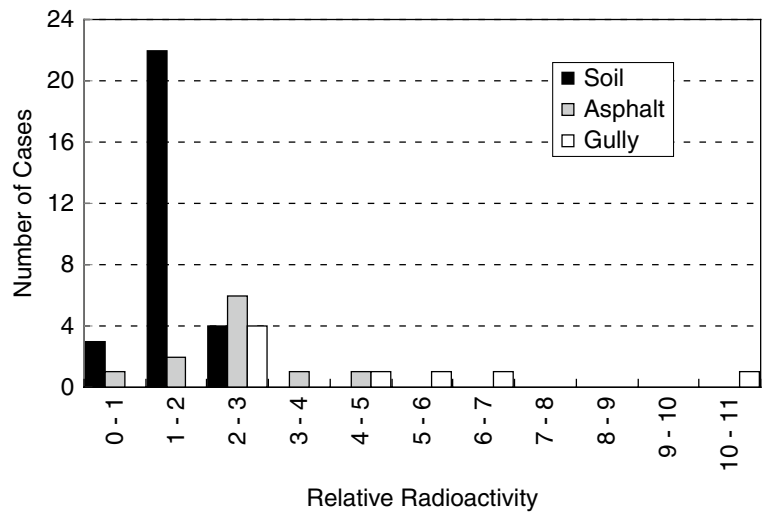

Fig. 8.8 Average activity on masks used during screening activity

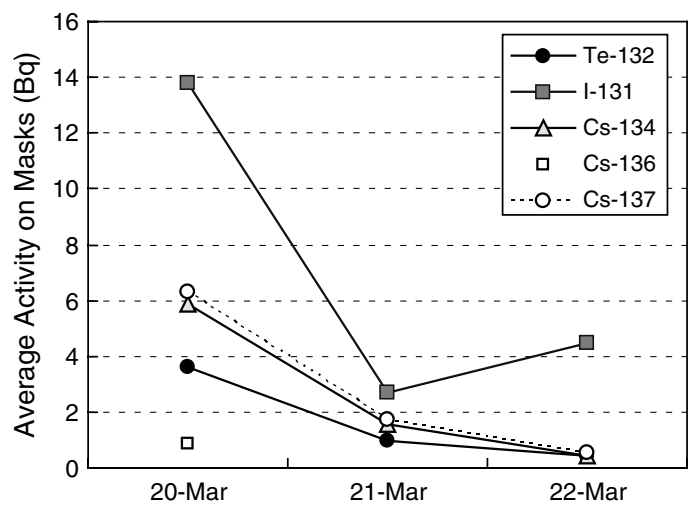

monitoring locations were very close to each other. Our observation discovered "hot spots" where radioactive material would accumulate with fine soil particles from its original deposit location owing to wind and rain.

A measurement of ground surface was conducted at two points in August 2011 in Namie town, which is located about $30 \mathrm{~km}$ northwest of the Fukushima Daiichi NPP. The result values were 54 and $175 \mu \mathrm{Sv} / \mathrm{h}$ (uncalibrated), which are 10-100 times higher than the results obtained at Ueno Park on March 30, 2011. In other words, serious contamination was observed.

\subsubsection{Radiation Exposure}

The radioactivity of the masks used on each day is shown in Fig. 8.8. Among detected nuclides, only ${ }^{136} \mathrm{Cs}$ was found in masks used on March 20 with ${ }^{131} \mathrm{I}$ showing a slightly different trend, and the radioactivity decreased faster than their own physical half-lives, which was caused by the difference in location of screening 
activity and time spent outdoors. During this screening activity, the effective dose (external exposure) was $0.1 \mathrm{mSv}$, and the committed effective dose (internal exposure) was $0.0327 \mathrm{mSv}$.

\subsection{Conclusion}

A GM-tube detector was calibrated with a standard cesium-137 $\left({ }^{137} \mathrm{Cs}\right)$ source and used for measuring radioactive contamination from the Fukushima Daiichi Nuclear Power Plant. The GM-tube detector used in this study was calibrated up to $4 \mu \mathrm{Sv} / \mathrm{h}$ based on a quadratic equation. This GM-tube detector yielded the same result as a $\mathrm{NaI}$ scintillation counter, and its practical use was validated under calibration.

Air dose rates were measured in Fukushima City, Iwaki City, Shirakawa City, and Samegawa Village and along the Tohoku and Banetsu Expressways during our screening activity in Fukushima Prefecture from March 19 to 22, 2011. Those rates in Fukushima City were highest, followed by those along Tohoku Expressway, whereas those in Samegawa Village and along Banetsu Expressway (both located in the Abukuma highlands) were relatively low. This radioactive distribution agreed with the MEXT reports consisted of airborne monitoring in April 2011. The radioactivity on masks used and the external and internal exposure was substantially low.

Acknowledgement We thank the Matsushimaya Ryokan staff for their support despite difficulties following the Great East Japan Earthquake and the subsequent nuclear accident. We thank Mr. Yukihiro Mizuochi for measuring the dose rates. This work was supported by KUR Research Program for Scientific Basis of Nuclear Safety.

Open Access This article is distributed under the terms of the Creative Commons Attribution Noncommercial License which permits any noncommercial use, distribution, and reproduction in any medium, provided the original author(s) and source are credited.

\section{References}

1. Hirose K (2012) 2011 Fukushima Dai-ichi nuclear power plant accident: summary of regional radioactive deposition monitoring results. J Environ Radioact 111:13-17

2. Ohta $\mathrm{T}$ et al (2012) Prediction of groundwater contamination with ${ }^{137} \mathrm{Cs}$ and ${ }^{131} \mathrm{I}$ from the Fukushima nuclear accident in the Kanto district. J Environ Radioact 111:38-41

3. Tagami $\mathrm{K}$ et al (2011) Specific activity and activity ratios of radionuclides in soil collected about $20 \mathrm{~km}$ from the Fukushima Daiichi Nuclear Power Plant: radionuclide release to the south and southwest. Sci Total Environ 409:4885-4888

4. Fukushima prefecture government. http://www.pref.fukushima.jp/nuclear/info/pdf_files/ H230615.pdf (in Japanese)

5. Japan Atomic Energy Agency, Distribution Map for Radiation Dose. http://ramap.jaea.go.jp/ map/

6. MEXT. http://www.mext.go.jp/component/english/_icsFiles/afieldfile/2011/05/10/1304797_ 0506.pdf

7. Katata $\mathrm{G}$ et al (2012) Numerical reconstruction of high dose rate zones due to the Fukushima Dai-ichi Nuclear Power Plant accident. J Environ Radioact 111:2-12 